\title{
A VIDA DE UMA FAMILIA IDOSA DE UMA VILA PESQUEIRA
}

\author{
Lúcia Hisako Takase Gonçalves* \\ Leony Lourdes Claudino dos Santos* \\ Irmgard Brueckheimer Roza*
}

\begin{abstract}
RESUMO - O trabalho é um estudo descritivo que focaliza um casal de idosos no contexto familiar e sócio-cultural numa comunidade pesqueira de origem açoriana. Com base nas informações obtidas através de dados da pesquisa de CARTANA (1988), fez-se uma descrição sumária do cenário da vila, para que o leitor possa melhor compreender o estilo de vida de seus moradores. A vida do casal, Seu José e Dona Maria, que é o ponto central deste relato, é descrita a partir da apresentação da estrutura familiar, de depoimentos pessoais, alguns transcritos de acordo com seu próprio modo de falar e da descrição e um dia comum de sua vida. São ressaltadas algumas implicações para a enfermagem e outros profissionais da saúde como: saúde, doença e envelhecimento, notando-se que estes são encarados com a mesma importância que os demais aspectos da faminia. É abordado seu comportamento em caso de doença quando procuram primeiramente os recursos comuns utilizados pela comunidade, depois a rede formal de atendimento à saúde. Chama-se especial atenção dos profissionais de saúde, mostrando que poderão desempenhar com eficiência suas funções, se considerarem, na assistência ao cliente, seu componente cultural de crenças, normas e práticas de saúde.
\end{abstract}

ABSTRACT - This is a descriptive study focusing on an aged couple in their family and socio-cultural context in a fishing community of Azorian descent. Based on data supplied by CARTANA's (1988) ethnographic study, a condensed description was made of the village scenery, se as to offer the reader a better understanding of the dwellers' life style. The couple's ("Seu" Jose and "Dona" Maria) life central point in this narrative is described according to family structure, personal statements, of which some are translated in their own peculiar manner of speech, and describe a common day in their life. Implications to nursing and to other health professionals are described, such as health, disease and ageing, approached here with an importance equal to that of other family aspects. This behavior in sickness is emphasized when first seeking common community resources and, thereafter, the formal health network. A special note is offered to health professionals towards a better performance if and when they take into consideration the clients' cultural components regarding health convictions, norms and practices.

\section{INTRODUÇÃO}

O presente trabalho tem o propósito de descrever o modo de vida de uma família idosa, moradora numa vila pesqueira localizada às margens da Lagoa da Conceição, na Ilha de Santa Catarina. Este local, uma região ainda pouco explorada, denominada, Costa da Lagoa é considerada hoje uma reserva biológica. O isolamento geográfico é um aspecto importante da Costa. O acesso à vila é difícil; só é feito através de tri has ainda construídas nos tempos dos escravos, as quais só podem ser transitadas a pé ou a cavalo. Por água, o transporte é feito através de barcos a motor ou por canoas a remo ou a vela. É uma vila pequena, com cerca de 1.000 habitantes, formada de aproximadamente 200 casas, encravadas nas encostas das montanhas e ao longo das margens da lagoa. Considerada ponto de atração turística, sua extensão aproximada é de $5 \mathrm{Km}$ de comprimento por $200 \mathrm{~m}$ de largura. Apesar de a maioria das casas ocuparem os terrenos planos da região, existem outras que se equilibram nas encostas, morro acima.

É uma localidade que dispõe de poucos benefícios públicos. Possui rede de luz elétrica recentemente instalada, uma escola de primeiro grau incompleto, um posto de saúde e serviço de transporte público (embarcação da prefeitura).

$\mathrm{O}$ abastecimento de água é rudimentar. Esta $\varepsilon$ captada pelos moradores, de córregos ou fontes mais próximos, através de mangueiras que servem a cada casa ou a um agrupamento de casas. A água é portanto consumida sem tratamento.

O lixo doméstico é depositado em buracos cavados nos quintais, ou à flor da terra e ocasionalmente queimados. Com respeito aos dejetos, são lançados diretamente nos córregos, sendo que umas poucas casas se utilizam de fossas. Os moradores não se preocupam com a poluição das águas, referem que o volume de dejetos é pequeno em relação à água da Lagoa.

As habitações dos moradores nativos apresentam grande uniformidade quanto ao seu aspecto. Elas são geralmente de tamanho pequeno, construídas de ma-

\footnotetext{
* Docentes do Departamentos de Enfermagem da Universidade Federal de Santa Catarina-Departamento de Enfermagem - C.P. 476, Florianópolis, Santa Catarina, CEP. 88.035.
} 
deira com fundações de tijolos ou pedras, um pouco acima do terreno, necessitando de uma escada de 2 a 3 degraus para se entrar. A cobertura é de telha de barro. Internamente, são divididas em sala, quartos e cozinha. As instalações sanitárias localizam-se fora de casa. É comum não dispor de chuveiro, sendo o banho tomado em bacia. O urinol é também bastante usado. A casa não costuma ter portas entre cômodos. Apenas o quarto do casal é separado por uma cortina de pano. As fachadas são dispostas de frente para o caminho, ou de frente para a Lagoa, possuindo de 2 a 3 janelas de cores vivas, contrastantes com a cor das paredes. As portas são laterais, geralmente, abrindo uma para a sala e outra para a cozinha.

As casas localizam-se próximas uma das outras para o aproveitamento do terreno. Os filhos e netos costumam construir suas casas no mesmo terreno dos pais. Como as famílias mais antigas são numerosas, as casas ficam muito próximas umas das outras e sem muros ou cercas entre elas. Assim sendo, é comum encontrar agrupamento de casas de um mesmo ramo familiar convivendo entre membros de várias gerações.

O quintal das casas geralmente é utilizado para o plantio do café, feijão, banana e mandioca. O café é colhido e torrado em casa, servindo para o uso diário. $\mathrm{O}$ feijão também é colhido para o uso familiar. Quanto a mandioca, é trocada por farinha nos engenhos mais próximos. Não é costume cultivar hortas na vila.

Seus moradores em sua maioria vivem da pesca, cujos produtos são usados para o sustento da família e parte deles para a comercialização. Como esta é pequena e não supre as necessidades de subsistência, os homens geralmente se dedica à pesca sasonal permanecendo por longos períodos afastados de suas famílias. As mulheres dedicam-se às atividades domésticas e colaboram no orçamento do lar com a confecção e venda de rendas de bilro. Não é um traço cultural as mulheres casadas trabalharem fora de casa, nesta comunidade. Apenas as moças, desde muito jovens, são empregadas em casas de família, geralmente conhecidas. As famílias mais antigas com membros idosos, são as que mais guardam os costumes culturais de sua origem açoriana demonstrada em seu modo de vida e atividades laboriais, familiais e sociais.

Estes mesmos traços culturais já foram identificados por ELSEN (1984), quando conduziu uma pesquisa qualitativa para identificar os conceitos de saúde e doença e comportamentos relacionados, em uma outra vila pesqueira na Ilha de Santa Catarina, cujos moradores também possuiam origem açoriana. Ainda, uma outra pesquisa conduzida por OLIVEIRA, no período $88 / 89$, para o estudo da qualidade de vida de pessoas idosas nativas da Ilha de Santa Catarina, moradoras em um bairro em fase de urbanização, identificou características culturais semelhantes no que tange ao modo de construção e localização das casas de um mesmo ramo familiar, bem como as suas maneiras de relacionamento.

Esta breve descrição retrata o cenário da vila que se constituiu o local de uma pesquisa etnográfica conduzida por CART ANA (87/88), cujos objetivos foram a identificação das redes de suporte social das famílias e as ações desempenhadas pelas mesmas. A rede de suporte social da família foi entendida pela pesquisadora como sendo "os contados pessoais mantidos com determinada freqüencia pe- los membros de uma família ou pela família como grupo, com indivíduos ou grupos externos, e de cujos contatos a família usufrui de algum tipo de suporte". Para a realização desta pesquisa de abordagem qualitativa, a autora valeu-se fundamentalmente do método da observação participante e para tanto instalou sua residência na vila e lá conviveu com a comunidade, durante seis meses, o que lhe permitiu aprender o significado cultural dos fenômenos que lá ocorriam, do ponto de vista das pessoas e das família como grupos.

Graças aos volumosos dados brutos constituídos de notas de campo, diário da pesquisadora e outros materiais coletados e documentados foi possível selecionar uma família idosa típica daquela comunidade, que passaremos a descrevê-la e cujos nomes serão substituídos pelos pseudônimos de Seu José e Dona Maria, e de Mariazinha, à neta que vive com eles.

Para a melhor compreensão do modo de vida desta família apresentaremos inicialmente o genograna, ou se ja, a representação gráfica da estrutura familiar, conforme se observa nas figuras $1,2,3$ e 4. No genograma a figura geométrica de forma quadrada refere-se a genros e noras. $\mathrm{O}$ número inscrito no interior da figura representa a idade, e o sinal mais $(+)$ representa falecido.

\section{Figura 1 \\ GENOGRAMA DO CASAL SEU JOSÉ E DONA MARIA}

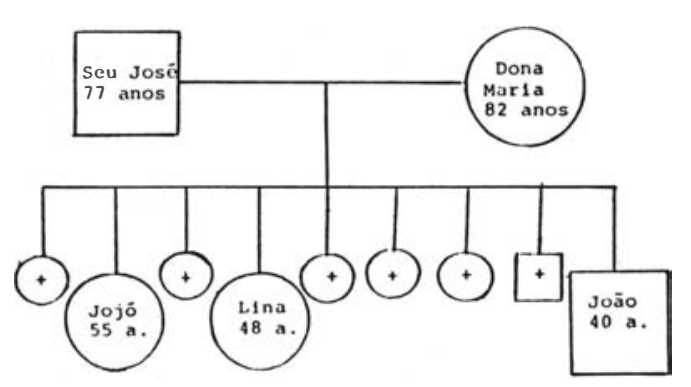

Conforme a figura 1 , o seu José conta com 77 anos de idade e D. Maria com 82. Tivera nove fïlhos dos quais três estão vivos, casados e vivem na mesma comunidade. Os filhos mortos tiveram uma vida curta de 3 a 8 meses com exceção de uma filha que morreu com 13 anos.

Devido a idade avançada, a deficiência visual do casal, à saúde precária de Dona Maria e à necessidade de ajuda nos afazeres domésticos, a neta Mariazinha de 15 anos, filha de João, que mora bem próximo, foi destacada, conforme o costume da comunidade, para desempenhar esta tarefa familiar.

Mariazinha faz todos os serviços domésticos da casa dos avós, inclusive companhia à noite, dormindo no mesmo quarto. Nos intervalos dos serviços, ela ia à casa dos pais para fazer renda para vender ou fazer seu enxoval e ao mesmo tempo assistir televisão. 

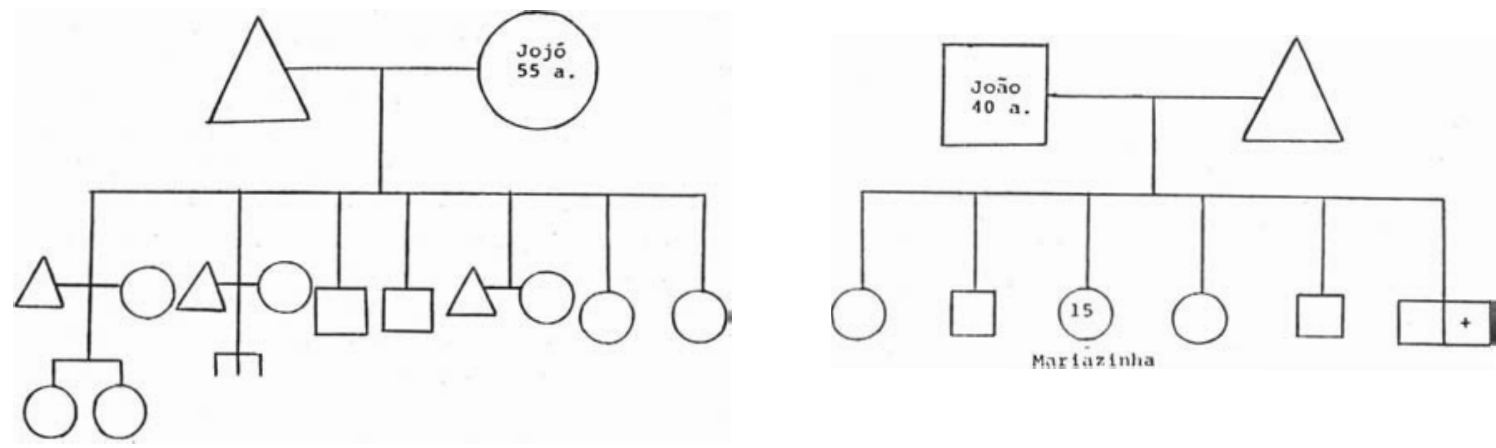

Mariazinha

Figura 4

GENOGRAMA DA FAMÍLIA DA FILHA

\section{LINA}

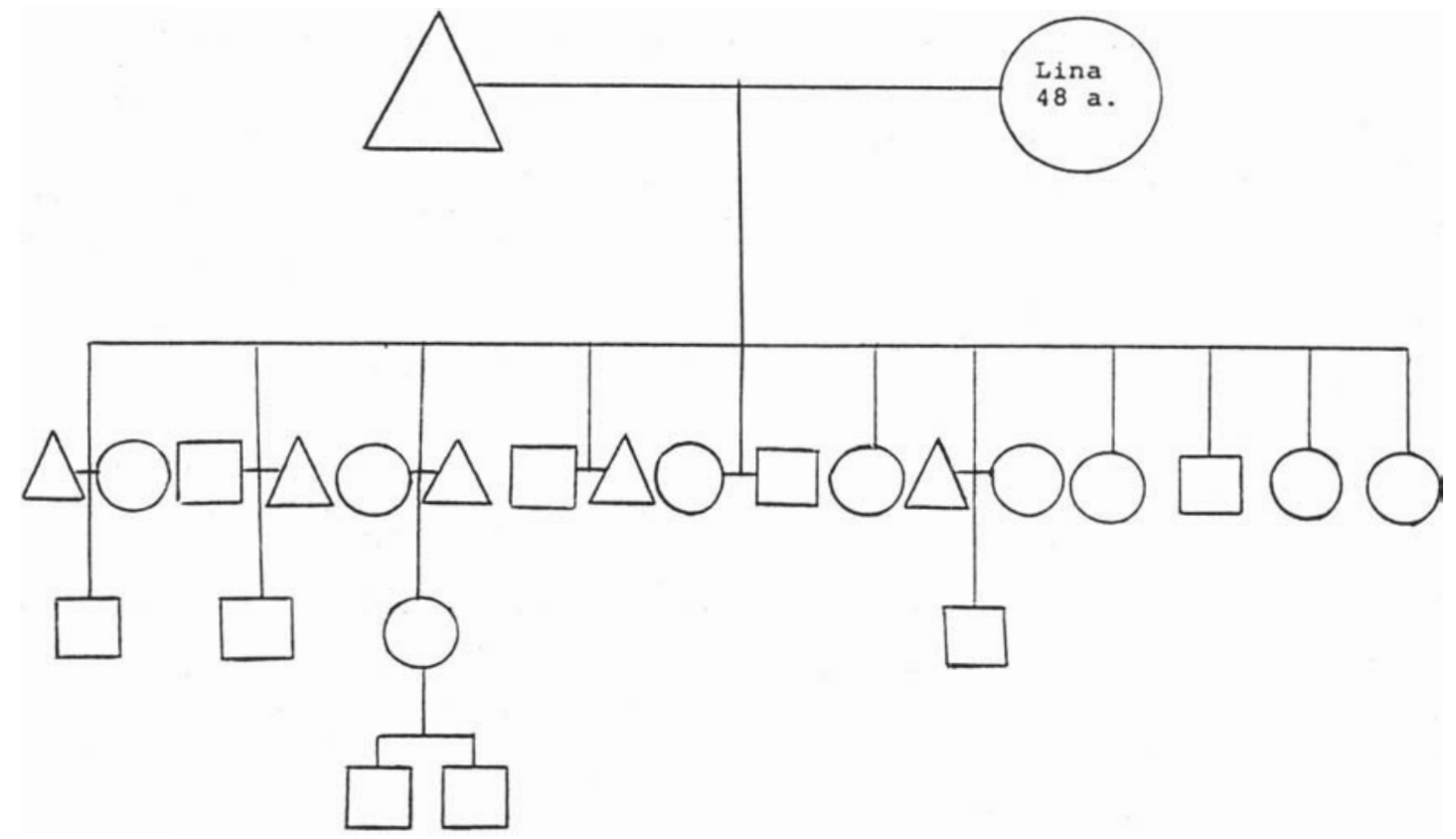

Como pode ser observado nas figuras 2,3 e 4, os filhos têm suas famílias constituídas dando a seu José e Dona Maria 24 netos, nove bisnetos e até 2 trinetos.

A maioria dos netos mora na comunidade embora exerça atividades fora da vila, enquanto outros ainda se ocupam da pescaria conforme o costume local, inclusive participando de pescaria sasonal, afastando-se temporariamente de suas casas.

Vale ressaltar que, ao observar o genograma da família, onde a $2^{\mathbf{a}}$ geração representada pelos seus três filhos, já está ultrapassando o estágio de reprodução, nota-se uma ligeira tendência à diminuição do número de filhos, embora ainda prevaleça o padrão cultural de família numerosa.

Apresentada a estrutura da família do Seu José e Dona Maria passaremos em seguida a descrever o seu modo de vida através do relato de um dia comum na vida do casal.

O cotidiano do casal Seu José e Dona Maria poderia ser caracterizado pela seguinte descrição: "primeiro de tudo, nós levantamos com o clarear do dia, lavamos o rosto e a boca, e cada um de nós pega uma caneca de café aparado (café com açúcar 
sem acompanhamento), que a Mariazinha coa, e bebemos sem sentar à mesa". "Isso quando estou boa" diz Dona Maria. Ultimamente tem se encontrado cada vez mais adoentada e acamada. Segundo Mariazinha, quando a vovó está doente, ela leva uma bacia d'água para a mesma se lavar, e depois serve o café, tudo na cama. Dona Maria diz que ao levantar-se, "sempre ando de meia e chinelo, por causa do frio que sinto e o medo da asma piorar". Após o café, diz o Seu José: "se o dia é de sol pego o chapéu, o cigarro de palha que eu mesmo faço com fumo de corda, e saio de casa. Visito as casas dos meus filhos e netos que moram todos no meu terreno, pertinho, logo â̂'. Dona Maria quando está bem, faz o mesmo, visita a casa dos mesmos filhos e netos. Em dias de chuva, vento sul, ou quando estão doentes, não saem de casa, ficam a ouvir programas populares de rádio. Enquanto isso, a Mariazinha cuida diariamente da casa, começando pela arrumação do quarto: dobra toda roupa, põe para arejar e/ou ensolarar na janela, varre o chão e depois recoloca a roupa na cama. Em seguida passa novamente no coador, o café que sobrou e prepara o acompanhamento para o segundo café. Isto ocorre, lá pelas 9 horas, eles não usam relógio. Este é o momento em que a família toda: seu José, Dona Maria e a Mariazinha sentam-se à mesa para a primeira refeição compartilhada do dia. Este café é tomado geralmente com salgados como peixe ou camara a frito; mandioca ou batata doce cozida; peixe com farinha; bolo ou pão, ou ainda "piroquinha" que é mistura de café, açúcar e farinha de mandioca. Terminada esta ref eição, a neta arruma a cozinha e se tiver roupa su ja, vai lavá-la, caso contrário vai à casa de sua mãe fazer rendas para ganhar seu dinheirinho. Enquanto isso o casal permanece em casa É a hora da Dona Maria receber as visitas. "Minha prima Ana que mora do meu lado, vem sempre, todos os dias conversar comigo. Os netos então, nem diga, não saem daqui’. Dona Maria, quando adoentada, recebe visitas no quarto. Estas sentam-se em volta de sua cama e lá conversam e trocam notícias e assim se mantem atualizada e conhecedora de tudo que ocorre na comunidade. Quando ela está bem, então recebe visitas sentada no banco da cozinha. O Seu José, geralmente, fica de pé na janela a olhar para fora, certamente mais atento na conversa e se abastecendo de notícias do que vendo o movimento lá fora, pois ele quase não enxerga. Quando vai chegando próximo ao meio do dia, a Mariazinha prepara o "jantar" assim chamado para a refeição das 12 horas. $\mathrm{Na}$ realidade, esta refeição não é servida neste horário. Acontece em torno das 11 horas. A base da alimentação é composta de feijão e farinha de mandioca. Às vezes usam o arroz. Acompanha sempre algum fruto do mar e as vezes carne de galinha que é comprada fora. Seu José diz: "eu gostó de galinha ensopada, mas a mulher gosta mais de canja" (sopa de galinha). $\mathrm{O}$ jantar é servido na mesa da cozinha. $\mathrm{O}$ feijão é passado no liquidificador. Este é primeiro servido ao Seu José, em um alguidar (cumbuca de barro) ao qual ele junta farinha para fazer o pirão. Em seguida é a Dona Maria a ser servida e depois os demais, a neta e quem mais lá estiver para tomar a ref eição juntos. É comum ver algum neto jantando lá. Não é costume usar o garfo, mas sim a colher. Quanto à faca, é usada apenas uma sobre a mesa. Terminada a refeição, o casal lava a boca por fora, com sabonete na única torneira existente na casa, na pia da cozinha. Dona Maria vai fazer o descanso da tarde que dura entre 1,5 a 2 horas. Este descanso é respeitado. Já o Seu José diz não gostar de dormir. ele fica andando prá lá e prá cá. A neta arruma a cozinha. Diz Dona Maria: "Depois do meu descanso da tarde, começa de novo a visitação. É a hora do entra e sai. Vem gente de longe, andando até $3 \mathrm{Km}$ ". Sua filha Jojó, que mora mais distante, faz sua visita costumeira aos pais. É com a visitação intensa de familiares, vizinhos e pessoal da vila que também vem para consultar, pois Dona Maria é benzedeira, que ela fica inteirada dos acontecimentos da vila. Ela é muito respeitada pelo pessoal da comunidade, também porque costuma benzer "sapinho", "susto", "mal olhado". Em torno das 15 horas, o casal toma outro café. Seu José diz: "eu gosto de café preto, mas ela gosta com leite". O leite é "arrepartido" (significa dar uma parte) pela neta que mora na frente. Este café é servido para todos que a estão visitando naquela hora. A visita continua até o entardecer. A ceia, assim chamada para a refeição da noite, é preparada usando quase sempre as sobras do jantar. É servida, assim que o dia escurece. Terminada a refeição, é costume o casal lavar a boca e se encaminhar para dormir. Em épocas de verão, eles demoram um pouco mais para se deitar. O banho não é diário, Dona Maria faz banho de assento na bacia, todos os dias. Ela se incomoda com o seu enorme prolapso de útero e, refere que por causa disso só se permite à relação sexual uma vez na semana. Diz ainda que por parte de seu marido, não haveria qualquer restrição na esfera sexual. $\mathrm{O}$ casal dorme num sofá cama aberto e a neta numa caminha, todos em um quarto só. Deixam uma luz acesa na sala, porque diz Dona Maria que tem medo de morrer no escuro e medo de que coisas ruins aconteçam à noite. O casal é católico mas só Dona Maria reza antes de dormir e vai à missa. Diz Dona Maria: “eu vou a todas as missas que são rezadas aqui. $\mathrm{O}$ padre vem rezar a missa cada duas semanas".

Pelo conhecimento do modo de vida desta família idosa típica, da comunidade com traços culturais de antepassado açoriano, podemos extrair algumas características relativas à saúde e envelhecimento com importantes implicações para a prática da enfermagem e de outras profissões de saúde.

A saúde, doença e o envelhecimento, segundo pesquisa de CART ANA (1988), são aspectos vividos e encarados em igual importância aos demais aspectos da vida da família, naquela comunidade. $\mathrm{O}$ seu trato segue as normas próprias da comunidade buscando apoio e suporte na rede social, que no caso da família em questão, é representada principalmente pelos seus familiares descendentes. As crenças e atitudes observadas no cuidado e/ou prevenção de certas doenças, agudização de doenças crônicas e deteriorização da saúde pelo envelhecimento, são próprias da comunidade. A benzedura é prática comum para doenças como: "ataque de bicha", "arca caída", "susto", "zipra", "mal olhado". Resguadar-se do vento sul, chuva e friagem nos pés é uma prática das pessoas idosas, como preventivo dos agravos de doenças respiratórias, reumatismos e outros males crônicos. Remédios comuns vendidos livremente nas farmácias e remédios 
caseiros são usados para a cura de muitas doenças. $\mathrm{O}$ agravo dos órgãos dos sentidos, como o da visão é en carado com resignação por acreditarem ser conse. qüência do passado ou próprio do envelhecimento. Estas constatações foram também identificadas nas pesquisas de EL SEN (1984), GONÇAL VES (1984) et alii e OLIVEIRA (1989). Quando os problemas percebidos não conseguem ser solucionados por meio de modos cotumeiros da comunidade, então o sistema formal é utilizado, que no caso de doença, compreende o hospital, ambulatório e a consulta ao médico. Este fato foi marcadamente observado, primeiramente na pesquisa de ELSEN (1984) e reafirmado na pesquisa posterior de CARTANA(1988).

A persistência daquelas práticas, nas comunidades estudadas, nem sempre saudáveis ou preventivas, ocorre em função, conforme relato dos informantes das pesquisas, do conforto que trazem, se ja pela atenção personalizada, contatos freqüentes e/ou duradouros e relacionamento familial, isto é, de conhecidos que pertencem à rede de suporte social. Assim, a prática do sistema formal de saúde só pode desempenhar suas funções com eficiência, na medida em que os seus profissionais, incluindo a(o) enfermeira(o), concordando com LEININGER (1985) considerem na prática do atendimento ao cliente, o seu componente cultural de crençs, normas e práticas de saúde. Considerem a importância e a necessidade do estímulo aos valores culturais positivos e da busca de um entendimento através de troca de idéias para a necessitada repadronização de certas práticas na saúde, doença e envelhecimento. Este comportamento profissional não pode prescindir de um relacionamento genuinamente humano, embora não possa pertencer à rede de suporte social do cliente, conforme as constatações de CARTANA (1988). Também é imprescindível a consideração dos membros da rede social, os quais são chamados por "a quem a gente confia", trazendo-os como co-participantes no tratamento e cuidado do cliente e, merecedores igualmente de toda atenção profissional.

\section{REFERÊNCIAS BIBLIOGRÁFICAS}

1 CARTANA, Maria do Horto Fontana. Rede e suporte social de famulias. Florianópolis, S.C., 1988/Dissertação de Mestrado em Enfermagem da Universidade Federal de Santa Catarina.

2 ELS EN, Ingrid. Concept of health and illness and related behaviors among Brazilian families living in a fishing village. San Francisco, CA, 1984/Doctoral Dissertation at UCSF, School of Nursing.

3 GONÇALVES, L.H.T.; SANTOS, L.L.C.; ELSEN, I. Significado do envelhecimento e saúde para o idoso em seu contexto familiar e sócio-cultural. Rev. do Centro de Ciências da Saúde/Universidade Federal de Santa Catarina. (no prelo).

4 LEININGER, M. Transcultural care, diversity and universality: a theory of nursing. Nursing and Health Care, 6(4):209-212, 1985.

5 OLIVEIRA, Clara R.B. de. Eu fiz tudo para se feliz-bem estar entre velhos asilados e não-asilados. Florianópolis, S.C., 1989/Dissertação de Mestrado em Antropologia da Universidade Federal de Santa Catarina. 